\title{
TRANSACTIONAL DISTANCE AMONG OPEN UNIVERSITY STUDENTS: HOW DOES IT AFFECT THE LEARNING PROCESS?
}

\author{
Amanda Kassandrinou, Christina_Angelaki[cangelaki@yahoo.com],Ilias Mavroidis_imavn@tee.gr], \\ Hellenic Open University, School of Humanities [wmw.eap.gr], Patras, Greece
}

\begin{abstract}
This study examines the presence of transactional distance among students, the factors affecting it, as well as the way it influences the learning process of students in a blended distance learning setting in Greece. The present study involved 12 postgraduate students of the Hellenic Open University (HOU). A qualitative research was conducted, using information collected via individual semi-structured interviews. Content analysis of the gathered information provided evidence regarding the existence of student-student transactional distance for several reasons, such as geographical and relatively limited face to face interaction. The role of the tutor as well as of the course provider were also examined in this respect. Finally the study indicated that the existence of perceived transactional distance among the students has a negative effect on their learning process.
\end{abstract}

Keywords: student-student transactional distance, blended course, distance learning, communication, interaction.

\section{Introduction}

According to Garrison (2000), within the past few years research on distance education has focused on transactional issues having to do with teaching and learning. This shift from structural to transactional issues observed at the beginning of the $21^{\text {st }}$ century introduces the post industrial model of distance education which focuses on constructs of interaction and communication. The identification of these constructs can provide us with useful information regarding the design of courses which meet better the learners' needs and foster the learning process. The wider range of theoretical notions has contributed into a deeper understanding of learners' needs. Transactional distance is one of these types of constructs (Chen, 2001a). Moore (1997) defines transactional distance as the psychological and communication space between the learners and the tutor due to geographical separation. The special teaching procedures required due to this separation fall into three clusters named Dialogue (communication between tutor and learners) Structure (elements of course design) and Learner Autonomy (control of students on their learning). At the same time he identified three forms of transactional distance, namely learner-tutor, learner-learner and learner-content interaction.

The expanded use of new ICT tools facilitates dialogue, communication, interaction and cooperation for participants in distance learning courses, generating thus an increased research interest regarding collaborative learning environments (Schellens \& Vackle, 2006). As a consequence, geographical distance should no longer be considered as a barrier. What is really important is gaining a deeper understanding of the communication and psychological gap among 
participants in distance learning courses as this may also be the key to successful teaching and learning results (Dabbagh, 2004). Perception of distance has a great impact on students of distance learning courses and it is tightly related to the fact that a great number of distance learners do not manage to complete their course (Simpson, 2003). Lack of dialogue may increase perceptual distance which could be linked with poor retention rates (Dron et al., 2004).

Most of the research conducted on transactional distance has focused on a particular dimension of transactional distance, namely the transactional distance that learners experience when separated from their tutor. The HOU, officially established through Greek Law 2552/1997, is a relatively new public educational institution and the only University offering exclusively distance education courses in Greece. In the framework of HOU, research issues - related to open and distance learning (ODL) - which have been considered important, include mainly quality and effectiveness of the offered distance learning courses, the use of ICT, the tutor's role as well as tutor-learner communication and interaction (Giossos et al., 2008).

Taking into consideration the importance of transactional distance in the context of distance education (Moore,1997; Garrison, 2000; Jung, 2001; Gunawardena \& McIsaac, 2004; Giossos et al., 2009) and the relatively few studies examining learner-learner interaction in this respect, the present study seeks to explore in qualitative terms, through a case study at the HOU, if distance learners experience transactional distance when separated from their fellow students and if this has an effect on their learning process and motivation.

\section{Theoretical framework}

Moore borrowed the notion of transactional distance from Dewey and Bentley (1949), who originally identified it as an element of the learning process, in order to form the "theory of transactional distance". Moore's theory of transactional distance describes transactional distance as communication gap and psychological space of potential misunderstanding between the behaviours of both tutors and learners due to their separation (Moore \& Kearsley, 1996). This notion is further refined by Giossos et al. (2009) in a review of the contemporary relevance of Moore's theory of transactional distance. More specifically, they stated that the particularities of space and time which pertain to tutor and learner characterising distance learning, create particular behavioural models for both of them, and increase the communication and psychological space between them as well as insufficient understanding of each other.

According to Moore (1997) this particular communication and psychological space between teachers and learners defined as transactional distance, is a function of the interplay among three variables: Dialogue, Structure and Learner Autonomy. Dialogue refers to the communication between instructor and learner and it is taken further than a simple two-way communication taking into consideration all kinds of interaction aiming at solving the learners' problems (Giossos et al., 2009). Moore (1997) does not focus on the frequency of interaction but on its quality as well as on the extent to which it enables distance learners to resolve the learning problems they may be experiencing.

Moore (1997) describes structure as the level of the course's rigidity and flexibility. More specifically structure refers to elements related to the course design, objectives, assignments, activities, the nature of the course assessment as well as to the extent to which the course meets individual learners' needs. The third factor, learner autonomy, is contingent upon dialogue and structure. It is a characteristic of learners who are able to exert control on their learning and manage it in a self-reliant manner. It can be affected by the dialogue and the course's level of rigidity and flexibility as well as by the extent to which learners are able to control the learning process (Giossos et al., 2009). Garrison (2000) noted that learner autonomy cannot be easily European Journal of Open, Distance and e-Learning - Vol. 17 / No. 1 
explained, as it may be related to personal autonomy of the learner or autonomy linked with the learning materials themselves. Finally, Kanuka et al. (2002) noted that both high and low levels of transactional distance may be accepted depending on the individual characteristics of each learner and his/her autonomy level.

Moore's transactional distance theory suggests the existence of an inverse relationship among these three variables (Gunawardena \& McIsaac, 2004). For instance, a course with rigid and inflexible structure can decrease the sense of learner autonomy as well as the quality of the dialogue between instructor and distance learners. Consequently the learners' sense of transactional distance increases. Yet, Moore (1997) adds that when structure drops below a particular threshold, even though he does not specify it, students' sense of transactional distance can significantly increase as they may feel confused and dissatisfied.

According to Moore and Kearsley (1996) successful teaching in distance learning environments relies on the extent to which tutor and institution can provide appropriate levels of structure as well as appropriate frequency and quality of tutor-student dialogue taking into consideration learner's autonomy. The tutor is the one to determine what is appropriate and it varies according to students' characteristics, level of instruction and content (Moore, 1997). Thereby, development of well-structured support materials and increase of quality dialogue may reduce transactional distance depending on individual learners' needs.

As noted in the introduction, Moore (1997) identified three forms of transactional distance: a) learner-tutor interaction b) learner-learner interaction and c) learner-content interaction. Yet, defining dialogue as interaction between tutor and learner distinguishes it from the other forms. He used dialogue rather than interaction in order to hypothesise the inverse relationship with structure in relation to transactional distance. Another form of interaction, learner-interface interaction, was added by Hillman, Willis and Gunawardena (1994) to the already identified forms of interaction aiming at accommodating the features of electronic teaching.

Several studies (e.g. Bischoff, 1993; Saba \& Shearer, 1994; Bischoff et al., 1996; Chen \& Willits, 1998; Chen, 2001a; Chen, 2001b; Zhang, 2003; Force, 2004) have been carried out in order to determine the empirical status of Moore's transactional distance theory. Although their results do not unanimously converge, they all confirm its importance and usefulness as a framework within which distance learning practice should be analysed.

Bischoff (1993) and Bischoff et al. (1996) verified the presence of structure, dialogue and transactional distance, carrying out a study exploring 221 postgraduate students' perceptions of transactional distance, dialogue and structure in distance courses delivered via interactive television. Having developed a rating scale for measuring these three notions they noted several important elements about the way in which a valid rating scale about transactional distance should be developed and validated (Zhang, 2003).

The concept of transactional distance was taken a step further by Saba and Shearer (1994) who proposed a system dynamics to examine the relationship between structure and dialogue in relation to transactional distance. They observed the existence of an inverse relation among dialogue, structure and transactional distance. They also noted that the more dialogue and learner control increase in a videoconferencing environment, the more structure decreases and subsequently the more the transactional distance reduces.

Chen and Willits, (1998) examined dialogue as in-class discussion in a videoconferencing environment and noted that dialogue contributes directly to learning outcomes and reduction of tutor-student transactional distance, while transactional distance is inversely associated with 
learning outcomes. Chen (2001a, 2001b) examined the effects of tutor-learner interaction, learner-learner interaction, learner-content interaction and learner-interface interaction on Web based learning environments. Chen approached transactional distance as an experiential situation and referred not to transactional distance but to perceived transactional distance.

Zhang (2003) suggested that students' perception of transactional distance and their engagement with learning were mainly not affected by transactional distance between students and teacher but from perceived student-student transactional distance. After having carried out a research involving students of online courses from Nepal and Iceland Lemone (2005) concluded that transactional issues are significantly affected by cultural influences. Dron, Seidel and Litten (2004) examining transactional distance in a blended learning course illustrated the inverse relationship that exists between structure and dialogue in such a learning environment.

Gokool-Ramdoo (2008) suggested relating transactional theory with the analysis model of student persistence of Deschenes (1996) which includes three axes of elements for exploring student persistence: a) cognitive, b) meta-cognitive and c) affective. Her approach extends Moore's theory beyond the field of pedagogy as issues such as student persistence are related not only to pedagogical aspects of distance education but also to administrative and organisational ones.

Force (2004) conducted a quantitative research on perceived transactional distance, autonomy, structure and dialogue with students of courses based on asynchronous computer mediated communication environments. The results of the factor analysis used to process the gathered data about autonomy did not confirm Moore's theory.

Dron $(2006,2007$ a , 2007b) introduced some new ideas in relation to transactional distance and elearning as he analysed structure and dialogue in terms of transactional control. He concluded that transactional control is linked with both the teachers and learners' choices. He also explored control issues related to using social software, including the possibility for structure to arise as dialogue's result.

\section{Research questions}

Data collection for the current study was guided by the following four research questions:

1. Do students experience any transactional distance between themselves and their fellow students and in which way do they perceive student-student transactional distance?

2. Which factors lead students to experience transactional distance with their peers?

3. Does perceiving transactional distance with other students affect the learning process?

4. In which way do students believe that learner-learner transactional distance can be reduced so that it does not inhibit the learning process?

\section{Methods}

\section{Context of Hellenic Open University}

Offering exclusively distance education courses to students throughout Greece and abroad since 1998, the HOU consists of four separate Schools, namely Humanities, Social Sciences, Science and Technology, and Applied Arts. It currently offers 6 undergraduate and 27 postgraduate courses, accommodating approximately 31,000 students with an approximately $1 / 20$ tutor to student ratio. All HOU courses are offered in Greek and are addressed to Greek adult students as well as to foreign ones, provided that they master the Greek language at an advanced level. 
Undergraduate students are awarded a degree upon successful completion of twelve course modules whereas postgraduate students are awarded a Master's degree upon successful completion of four course modules and a dissertation. There is also possibility for $\mathrm{PhD}$ degrees.

Throughout the 10-month academic year HOU students must hand in three to six written assignments for each course module they have enrolled in. Furthermore, they must sit exams successfully at the end of each course module in order to successfully complete it. Each course module includes five face-to-face Counselling Group Sessions (CGS) which take place in nine cities all over the country for undergraduate courses and in three cities for postgraduate ones. In this sense, it can be considered as a blended learning method. Students are not obliged to participate in these CGS. It is up to students to plan their own study during each course module, i.e. studying the course material, working on the proposed course activities, and handing in the written assignments in time while they are continuously supported by the academic staff.

Tutor-student communication and interaction within the time span between CGS is mainly held via e-mail and telephone. Additionally, there is a web-based instructional environment / portal (http://online.eap.gr) wherein each course has its own website and whose use and capabilities are gradually increasing. Course websites simplify organizational procedures and enrich students' learning opportunities and experiences while providing possibility for asynchronous interaction both between tutor and students and among students as well.

\section{Survey tool}

This study aimed at exploring in qualitative terms a relatively new area of research looking for new insights regarding perceived transactional distance among students. Qualitative research focuses on understanding specific situations as well as communicating that understanding through description (Bradley, 1993). This description consists of what the participants stated even though there is a selection and interpretation of their words. The unavoidable distortion that lies in this selection and interpretation of the participants' words is countered by the tapescripts and the fact that they were invited to have access to the outcome of the study if they wished to do so.

A deductive approach to data collection was followed. Semi-structured interviews consisting of open-ended questions was the main technique used for collecting data. According to the purposes of the study the questions of the interviews were based on six themes which orientated the study and contributed to the analysis of the results and to the deduction of conclusions. The themes were the following:

1. demographic features,

2. students' perception of transactional distance,

3. frequency of communication and interaction,

4. factors that contribute to the increase of transactional distance,

5. the impact of this increase on the learning process and,

6. ways in which transactional distance can be reduced.

Twelve participants were interviewed in total: ten in person and two by phone. The interviews were approximately 20 minutes in length and were held in June 2012. The interview participants were informed about the purposes of the research before the interview. The researcher assured their anonymity. Participation was voluntary. The transcriptions of the interviews and the notes of the interviewer were analyzed with a view to identify the students' perception of transactional distance and its impact on the learning process, in response to the research questions set above. 


\section{Sample}

Taking into consideration the purposes of the study a convenient sample of $5 \mathrm{HOU}$ postgraduate students was initially selected. According to Cohen et al. (2007) convenient sampling involves subjects that are close to the researcher. The researcher simply chooses subjects that meet the requirements of the study's purposes and to whom he or she has easy access. In this case the researcher does not aim at generalizing the conclusions of the study (Cohen et al., 2007). The rest of the students were selected using the technique of avalanche sampling as they where chosen among students who were proposed to the researcher by the first five students who accepted to take part in the research. According to Cohen et al. (2007), in avalanche sampling the researcher tracks a proper group of subjects who subsequently work as "informants" helping the researcher to track new proper subjects. Following this approach, in this study 12 students, who met the requirements, were selected. The requirements were that they were adults, they all had obtained a degree attending conventional university courses and they were HOU postgraduate students having experience in distance learning. As far as the number of the interviewees is concerned, Terre Blanche et al. (2006) consider that this amount of responses is adequate if relatively brief, semi-structured interviews are held by a researcher on issues related to attitude and perception.

\section{Data analysis}

The data collected for this qualitative study were analysed using the technique of content analysis, a technique often used in analysing data collected in terms of a qualitative research. Using this particular technique researchers aim at describing, listing and composing the information collected from the subjects (Bird et al., 1999). Data were derived from analyzing the tapescripts and the notes taken, plus the notes based on the observation of the participants during the faceto-face interviews. The content analysis of the interviews was based on the six themes set out during the description of the survey tool, which were also used for categorizing the open ended questions addressed to the subjects. These themes were tightly related to the four research questions of the study.

\section{Findings and discussion}

The results below indicate a selection of the most relevant sections of the responses, as quotes and/or summaries of the participants responses paraphrased by the researcher, were organised and coded within each of the six themes tightly related to the four research questions of the present study. Due to the volume of the responses, it was not possible for all of them to be recorded.

More specifically, themes 2 and 3 are related to the first research question about students' perception of transactional distance with their peers and the way it is perceived, while theme 4 is related to the second research question about factors contributing to the presence of transactional distance among students. Theme 5 is linked with the third research question about the effect of transactional distance on students' learning process and finally theme 6 is linked with the fourth research question about the ways they believe transactional distance with their fellow students can be reduced. Theme 1, demographic features, is mainly related to the first question, but is also examined in relation to all research questions.

\section{Theme 1: Demographic}

Female interview participants outnumbered male participants (7 woman vs. 5 men). Everybody was aged between 30 and 45 years old. They were students of three out of the four Schools of HOU. They were attending or had recently attended 8 out of 27 postgraduate courses offered by European Journal of Open, Distance and e-Learning - Vol. 17 / No. 1 
HOU. More specifically, four students attended three different courses of the School of Human Studies, three students attended two different courses of the School of Social Sciences and five students attended three different courses of the School of Science and Technology.

According to Giossos (2009) transactional distance is an experiential situation that is perceived by students. Therefore this transactional distance is perceived in different ways by each student depending on his/her cultural and educational background. The fact that all the participants had almost the same cultural background, i.e. being Greek students who came mainly from parts of Northern Greece as well as being postgraduate students having obtained a degree from a conventional undergraduate course permitted the hypothesis that transactional distance was perceived by them in a similar way.

\section{Theme 2: Perception of student-student transactional distance}

\section{Perception of transactional distance}

Responses to the questions about presence of transactional distance between each participant and his/her fellow students, the degree to which they perceive it and what kind of distance they perceive it is, showed that the great majority of the interviewees $(n=11)$ perceived the existence of transactional distance between them and their peers. More specifically they stated that there was good contact only with few students while there was little or no communication at all with the rest.

\section{"[transactional distance]...yes, there is, apart from very few students that we keep in touch mainly for cooperating and not for socialising..."}

Trying to quantify the existence of transactional distance between them and their fellow students, five of the respondents talked about fellow students with whom they had no contact at all or they had little contact. The rest responded that they experienced much transactional distance with their peers considering the absence from CGS as a main reason for this. Three participants commented on the degree to which they perceive transactional distance.

"...Little [transactional distance] with some of them but too much with most of them. Only 5 CGS are held. I was usually absent or some of my fellow students were. So I had never met many of them... I met some of them for the very first time during the final exams."

".. Very little [transactional distance], with the ones I am in frequent contact and much [transactional distance] with the ones I have no contact at all."

"...too much [transactional distance], as I had little contact with very few of my fellow students due to my frequent absence from the CGS."

Face-to-face communication is still considered essential by students in the framework of their distance learning course (Loizidou-Hatzitheodoulou et al., 2001; Wilson \& Whitelock, 1998) while human contact is one of the main concerns of students and tutors who are experienced in conventional educational programmes and participate in distance learning courses (Parrott, 1995).

Ten students also commented that they perceived transactional distance as geographical noting that if they lived closer to each other, they would probably have been more in contact with their fellow students. This suggests that geographical distance is still an important descriptor within transactional distance concept. Furthermore, students perceived this distance as communication and interaction gap $(n=6)$ as well as psychological space $(n=2)$ between them and their peers, which is in agreement with the core notion of the transactional distance theory (Moore \& 
Kearsley, 1996). Finally two students perceived it as a gap of co-understanding whereas two others as awareness gap.

\section{Theme 3: Frequency of communicating and interacting}

Most of the respondents $(n=7)$ hesitated to contact their peers or considered unnecessary to take the first step to communicate and interact with the other students, mainly during the CGS. This is in accordance with other studies on student-student communication and interaction in the framework of HOU courses (Angelaki \& Mavroidis, 2013; Tzoutza, 2010; LoizidouHatzitheodoulou et al., 2001). Yet, the rest of the respondents claimed that they take initiative for starting dialogue with their fellow students both during and between the CGS. All of them stated that between the CGS, they kept in touch with maximum two of their fellow students whereas they interact with many more during the CGS. Conrad (2005) considers course design as a main factor for encouraging student-student communication and interaction. A carefully designed course should include venues for chat, for asynchronous interaction as well as group functions and lounges for social activities boosting communication and fostering a sense of community among learners. Tzoutza (2010) in a research examining HOU students' perception of CGS stresses the importance of promoting student-student communication not only during face-toface meetings but between them as well. Restricted student-student communication and interaction as well as hesitance to contact their peers can also be attributed to the low perceived value that students attribute to communication with their peers (Loizidou-Hatzitheodoulou et al., 2001) or to each student's temperament (Tait, 2003). A participant attributing contact with peers to her sociable and friendly character commented:

"... yes I do [take initiative to communicate with peers] because this is the way I usually act. When I like somebody I am usually the first to take initiative to approach them..."

While another one stated:

“...not much, I don't usually take the first step for communication. Between CGS I contact them only if I feel comfortable with somebody during the CGS first..."

Face-to-face meetings are also considered as a significant starting point for student-student interaction, a fact that is consistent with Conrad's (2005) study on blended courses considering face-to-face interaction as a benchmark of communication among learners.

Students showed their preference for contacting their peers mainly by phone, valuing its immediacy, and secondly by e-mail. Very few had the opportunity of meeting face-to-face between the CGS. This is in accordance with other studies (Angelaki \& Mavroidis, 2013; Tzoutza, 2010; Anastasiades \& Iliadou, 2010; Loizidou-Hatzitheodoulou et al., 2001) where distance learning students commented on the means of communication that they prefer to use for contacting their peers in case they have questions related to the course material or the assignments. More specifically, some participants stated:

\footnotetext{
"[keep in contact]... by phone or e-mail with two [fellow students], mainly between the CGS discussing only about the assignments..."

"We keep in touch between the CGS by phone and sometimes we meet each other or occasionally by mail about the written assignments..."

"...we usually talk about the assignments, questions having to do with the chapters we have to study, the tutor who has delayed sending comments on our assignments or sometbing similar... by phone or e-mail..."
} 
Regarding the way of communicating with their peers that made them feel closer to their fellow students they kept in touch with, most of them stated that they mainly preferred to communicate by phone $(n=7)$. Communicating by phone is an easy and convenient way of communication offering immediacy and prompt answers to queries (Sarakatsanou, 2007; LoizidouHatzitheodoulou et al., 2001; Wilson \& Whitelock, 1998). There were five students that referred to face-to-face communication and there were only two references to e-mail, proving the impersonal aspect of this means of asynchronous computer mediated communication. E-mail is mainly used for sending documents and not for discussing in order to find answers for their queries related to the assignments. Some participants commented:

$$
\begin{aligned}
& \text { "...by phone of course...I want to listen to the other's voice..." } \\
& \text { "...by phone and then face-to-face... but mainly by phone..." } \\
& \text { "Face-to-face, I prefer it. Actually, it's my favourite one... secondly by phone..." } \\
& \text { "Face-to-face is better but due to distance I prefer the telephone as it is a quality means of } \\
& \text { communication, too. Seldom by mail, only in case I have to send or receive some documents." }
\end{aligned}
$$

Overall, though students mainly preferred telephone as a means of contacting their peers and discussing issues in relation to their studies, they also stressed the fact that face-to-face interaction is ideal for interacting but it is difficult because of their overcharged schedule due to familial, professional and social responsibilities as adults, not to mention the geographical distance.

The reasons for which the participants sought to contact their fellow students were mainly issues related to the written assignments, the CGS and the tutors. In addition, they talked about problems related to their jobs especially students who were colleagues. Students who felt closer to each other also contacted their peers to discuss some personal problems. Finally they communicated with their fellow students when they looked for emotional support, mainly about problems having to do with their studies. Interaction with peers satisfied all of the participants. They felt pleased and satisfied because discussing with their fellow students encouraged and supported them emotionally as they shared their stress and frustration about studying and meeting the course requirements. In addition, they often found answers to questions having to do with the course material and the written assignments, a fact that increased their satisfaction. Some participants stated:

$$
\begin{aligned}
& \text { "... without their help and support, I would have dropped out..." } \\
& \text { "... [contacting fellow students] it helped me, as I shared my stress and I noticed that I wasn't } \\
& \text { the only one with similar queries... so I felt a bit better..." } \\
& \text { "...Yes, I am [satisfied]. Most of the times discussing something about questions [related to } \\
& \text { assignments] led to solutions..." }
\end{aligned}
$$

These findings are in consistence with the notion that student-student communication is a really significant and helpful factor contributing to the emotional well being of students in distance learning courses (Conrad, 2005; Tzoutza, 2010; Angelaki \& Mavroidis, 2013). 


\section{Theme 4: Factors increasing transactional distance among students}

\section{Reasons for development of transactional distance among students}

Trying to track the reasons that make students' perception of transactional distance increase, the findings showed that students considered geographical distance $(n=7)$ and the small number of CGS $(n=5)$ as well as the fact that their attendance was not compulsory $(n=2)$ as major factors leading students to perceive an increased level of transactional distance between them and their fellow students. Furthermore, overcharged schedules - and consequently lack of spare time - is another barrier for students, impeding the development of student-student dialogue and increasing transactional distance among them. Some participants commented characteristically:

"... [Geographical] distance and the fact that presence at the CGS is not compulsory mean that many students are not present at the CGS. So, we can't meet and get to know each other better..."

"... Geographical distance is large. We come from different parts of Greece and we meet our peers once every two months when the CGS are held and it's only for 4 hours..."

"... mainly [geographical] distance and lack of free time..."

“...the responsibilities that each one of us has... working... family... very limited free time. The fact that we live far away..."

Students of distance learning courses in higher education are adult learners usually overwhelmed by professional social and family responsibilities depriving them of free time and often having a negative effect on their studies (Miller, 2008; Liu et al., 2004; Moss, 2004). Lack of free time seems to be associated both with the lack of communication between the CGS and with the frequency of presence at them, therefore increasing the feeling of distance between students and their peers. In addition, the fact that all students had obtained their undergraduate degree attending conventional university courses could justify their tendency to consider geographical distance as a main factor of increasing transactional distance.

Different backgrounds and lack of common interests were two reasons reported by one student. Another one also referred to the restricted development of the web based instructional environment / portal of the distance learning provider (HOU), providing restricted opportunities for asynchronous and - especially - synchronous CMC and therefore discouraging learnerlearner communication and interaction leading to increased perception of transactional distance. According to Dron et al. (2004) and Stein et al. (2005) who studied transactional distance issues in blended learning environments, opportunities for learner-learner interaction should be part of course design cultivating and nurturing a collaborative online community, where transactional distance shrinks making geographical distance less relevant.

The reserved personality of some students was referred as a factor impeding communication and interaction among peers by one of the students. This is in accordance with other studies which consider that some students' introversion is an inhibiting factor regarding development of dialogue among students (Tait, 2003; Saenz, 2002; Angelaki \& Mavroidis, 2013). Additionally a great number of the participants claimed that tutor's lack of interest in encouraging communication, interaction, cooperation and a sense of community among learners was a significant factor for increasing perception of transactional distance between them and their fellow students $(n=7)$. A participant observed: 


\begin{abstract}
"... Not all of them [tutors], unfortunately very few did it [encourage communication among students] by electronically forwarding the list with the students' emails and phone numbers to each student of the group, by setting group activities during the CGS in order to encourage interaction. That was really belpful as it made us feel closer to our fellow students. It considerably helped us as compared to other tutors whose course planning didn't involve such activities..."
\end{abstract}

The important role of the tutor in encouraging quality communication and interaction among students of distance learning courses is stressed by several researchers (Conrad, 2005; Stein et al., 2005; Tzoutza, 2010; Pavlakis \& Kaitelidou, 2012; Angelaki \& Mavroidis, 2013). Moreover Anderson and Dron (2011) noted that in a course in which the ideal of low transactional distance is set as a goal, the tutor should assume a facilitative role as far as issues of dialogue and communication are concerned. Finally, Farquhar (2013) seeing the amount and quality not only of tutor-student dialogue but learner-learner dialogue as well, metaphorically calls the instructor a " traffic cop" who ideally ensures that each learner who enters the flow would feel safe to progress cooperating with other students, would share the road and stop long enough allowing others to traverse and progress.

\title{
Theme 5: The effect of transactional distance on the learning process
}

\section{Role of transactional distance in the learning process}

The responses of the students showed that the lack of communication or the restricted interaction with their peers, i.e. the presence of transactional distance, has a negative effect on their learning process as well as on the completion of their studies. Building relationship with their classmates was considered highly important and was related to the motivation and persistence in their distance learning course by six participants. Some of the respondents were convinced by their fellow students not to abandon their studies, although they had seriously considered it due to reasons such as financial difficulties, having failed the final exams or lack of time because of multiple responsibilities. One of the participants stated:

\section{"...Yes they [peers] belped me a lot! They actually talked me out of dropping out. They motivated me and persuaded me about the value of the Master's degree..."}

In addition, all of the students knew a case of somebody attending a distance learning course who thought about dropping out. Some of them did it but for some others tutors' or/and peers' support was significant in making them change their mind. Building a sense of community and social relationships with tutors and fellow students provides a key support system for learners of distance learning courses (Anderson, 2003; Barker, 2003; Richardson \& Swan, 2003; Rovai \& Baker 2005; Müller, 2008).

The responses also showed that meaningful interaction with peers, and therefore low transactional distance, was a significant aspect of the participants learning communities. Most of the respondents' feeling of satisfaction, motivation for their studies and sense of intimacy was derived from interaction with their fellow students during the CGS as well as between the CGS for preparing the written assignments set by the tutor (Müller, 2008; Herbert, 2006; Richardson \& Swan, 2003).

Yet, there were several students $(n=4)$ who considered interaction with their fellow students as an important aspect of their studies but not absolutely necessary as they "... can meet the requirements of the course without interacting with them [peers] or being in need of their support." Some others $(n=2)$ stated that they do not consider communication with peers 
important at all in the framework of their studies. The above could be related to the learners' degree of autonomy which is mainly a personal trait on the grounds that mature learners with high levels of autonomy might be able to manage their learning easily (Benson \& Samarawickrema, 2009). The students' temperament and mentality as well as the low value attributed to student-student communication may also lead them to attribute little or no importance to it during their studies (Tait, 2003; Loizidou-Hatzitheodoulou et al., 2001).

\section{Theme 6: Ways of reducing student-student transactional distance}

\section{How can the transactional distance among students be reduced?}

When asked to suggest ways that they believe would help to reduce transactional distance among peers, participants made several suggestions. In particular, concerning the provider, (HOU) they asked for more CGS meetings as well as their decentralisation (since they take place only in three cities for the postgraduate courses). The important role of CGS in fostering interaction, and therefore reducing transactional distance in blended courses, is also stressed by other researchers (Benson \& Samarawickrema, 2009; Dron et al., 2004). Respondents also mentioned decentralisation of some social events (e.g. graduation ceremony) and of the facilities offered, such as library services and study centres. A respondent stated:

\section{"...more centres around the country would mean less geographical distance. In this way they [students] would be able to communicate face-to-face more easily and frequently between the CGS.”}

Students also suggested that the HOU portal should be improved in order to encourage students both regarding synchronous and asynchronous $\mathrm{CMC}$; in this way the feeling of learning community would be reinforced as communication and interaction among peers would be easier and prompt. One student also referred to the possibility of implementing Counselling Group Teleconference Sessions. Mavroidis et al. (2013) note that teleconference is only recently being used in Greece as an advanced ICT tool in education, mainly in pilot applications. Widespread use of teleconference by the HOU would require the development and use of appropriate, mature, tools as well as the training of both students and tutors. Up to now, HOU seems to adopt a more traditional approach focusing more on learner autonomy and independence rather than on collaborative approaches and discourse (Angelaki \& Mavroidis, 2013).

The important role of the tutor in facilitating communication and interaction among learners as well as in building a sense of community in several ways in distance learning courses is stressed by many researchers (Anderson, 2003; Dron et al., 2004; Clair \& Fite, 2005; Conrad, 2005; Farquhar, 2013). Most of the respondents in this study asked for "friendly teachers" who will use collaborative approaches of teaching and whose course planning will be mainly focused on group activities encouraging cooperation and team spirit. According to Terhemba (2006), assigning group activities is an important factor for increasing interactivity and a sense of belonging to a community among distance education students. Moreover, a few students thought that the tutor would definitely help communication to increase by forwarding to students the contact details of their peers from the very beginning of the course. Finally some students suggested that it would be helpful if tutors were willing to organise some kind of social meetings so that the students could meet somewhere out and discuss about things having nothing to do with the course. A participant characteristically said:

"As for the teacher, more group activities are essential and why not organising friendly catch up meetings with peers somewhere outside the classroom... to encourage socialising with our classmates.” 
Finally, concerning what the students themselves can do to decrease transactional distance between them and their fellow students, respondents stressed that students should take more initiative for communicating with their peers, not only during but also between the CGS. Additionally, they should seek to use more frequently the portal of HOU which mainly provides possibilities for asynchronous ways of CMC and interaction with their peers such as chats and forums which contribute significantly to the promotion of student-student communication and the reinforcement of the sense of community among learners (Conrad, 2005; Stein et al., 2005; Tzoutza, 2010).

\section{Conclusion}

In conclusion, students perceive that transactional distance exists between them and their peers and attribute it mainly to the geographical distance, which separates them from their fellow students. This fact results in restricted communication and interaction among them. Students' mentality and temperament, the important role of the tutor in encouraging student-student communication as well as the restricted opportunities for interaction offered by the course provider (in this case $\mathrm{HOU}$ ) are also considered as possible reasons related with the presence of transactional distance among learners.

Moreover the value of the psycho-emotional aspects of the support from peers is obvious from this study. Many students, who had seriously considered abandoning their studies finally did not do so, thanks to the support and encouragement that they received from some of their fellow students. The problem is that communication is restricted. Students communicate essentially only with very few of their peers while there is absolute lack of communication with the rest especially during the time span between the CGS. Several ways of reducing this communication gap among students were proposed by the interview participants. Suggestions involved action taken from all parts, that is to say students, tutors as well as the distance learning provider (HOU).

Another finding of the present study that can have a considerably positive effect on distance learning practice is the tutor's essential role as communication facilitator. The tutor is supposed to continuously facilitate, foster and encourage quality communication and interaction among students. Furthermore, the students themselves should realise their own responsibility regarding the communication space they perceive between them and their peers. Finally, as noted above, as far as the institution (HOU in this case) is concerned, the findings of this study could be a starting point for considering ways of decreasing transactional distance among students as well as improving the learning results. According to Garrison (2009), distance education has not fully embraced the collaborative potential of online learning and therefore there is a need for distance education to further address issues of collaboration and community. For instance, the use of ICT collaborative tools such as teleconference, could contribute to the creation of an enabling environment for interpersonal communication and to the development of an online learning community, which - in combination with the face-to-face CGS - can assist in decreasing transactional distance.

It should be noted though, that there are certain limitations which may have influenced the findings of the present study. One limitation is that the findings cannot be generalized due to the nature and the rather small sample of the study. A larger sample would enable further investigation of presence of transactional distance among students and the effects on learners' learning process. Focusing only on postgraduate students could be perceived as another limitation although both graduate and postgraduate students share the essential element of being adult learners in an open university. Future studies could focus on undergraduate students and possibly on comparing results between postgraduate and undergraduate students. Finally, aiming 
at an in depth understanding of the transactional distance theory, it would be very useful to investigate in an integrated manner all the dimensions of transactional distance including tutorlearner, learner-content and learner-interface transactional distance. Building on the present study we plan to design a large survey that will allow for a wider generalisation of the findings.

\section{References}

1. Anastasiades, P. and Iliadou, C. (2010). Communication between tutors- students in DL. A case study of the Hellenic Open University. In European Journal of Open, Distance and E-learning, 13(2). Retrieved on April 10, 2012 from: http:/ $/$ www.eurodl.org/index.php?p $=$ archives\&year $=2010 \&$ halfyear $=2 \&$ article $=407$

2. Anderson, T. (2003). Getting the Mix Right Again: An updated and theoretical rationale for interaction. In International Review of Research in Open and Distance Learning, 4(2). http://www.irrodl.org/index.php/irrodl/article/view/149

3. Anderson, T. and Dron, J. (2011). Three Generations of Distance Education Pedagogy. In International Review of Research in Open and Distance Learning, 12(3), (pp. 80-97).

4. Angelaki, C. and Mavroidis, I. (2013). Communication and Social Presence: The impact on adult Learners' emotions in distance learning. In European Journal of Open, Distance and eLearning, 16(1), (pp. 78-93). http://www.eurodl.org/materials/contrib/2013/Angelaki_Mavroidis.pdf

5. Barker, S. (2003). Introducing group work and communication skills for external students: an analysis of the use of asynchronous online tools. In G. Crisp, D. Thiele, I. Scholten, S. Barker \& J. Baron (eds.), Interact, Integrate, Impact: Proceedings of the 20th Annual Conference of the Australasian Society for Computers in Learning in Tertiary Education. Adelaide, 7-10 December 2003.

6. Benson, R. and Samarawickrema, G. (2009). Addressing the context of e-learning: using transactional distance theory to inform design. In Distance Education, 30(1), (pp. 5-21).

7. Bird, M.; Hammersley, M.; Gomm, R. and Woods, P. (1999). Educational Research in Practice. Study Manual. Patras, HOU Press.

8. Bischoff, W.R. (1993). Transactional distance, interactive television, and electronic mail communication in graduate public health and nursing courses: Implications for professional education. Unpublished doctoral dissertation, University of Hawaii.

9. Bischoff, W.R.; Bisconer, S.W.; Kooker, B.M. and Woods, L.C. (1996). Transactional distance and interactive television in the distance education of health professionals. In American Journal of Distance Education, 10(3), (pp. 4-19).

10. Bradley, J. (1993). Methodological issues and practices in qualitative research. In The Library Quarterly, 63(1), (pp. 431-449).

11. Chen, Y.J. (2001a). Transactional distance in World Wide Web learning environments. In Innovations in Education and Teaching International, 55(4), (pp. 327-338).

12. Chen, Y.J. (2001b). Dimensions of transactional distance in World Wide Web learning environment: A factor analysis. In British Journal of Educational Technology, 52(4), (pp. 459-470).

13. Chen, Y.J. and Willits, F.K. (1998). A path analysis of the concepts in Moore's theory of transactional distance in a videoconferencing learning environment. In The American Journal of Distance Education, 13(2), (pp. 51-65).

14. Clair, R.S. and Fite, S. (2005). Far off Voices: Social Capital and Distance Education. In A. Lionarakis (ed), 1st Panhellenic Conference for Open and Distance Education. Pedagogical and Technological Applications. Conference Proceedings. Vol. A, (pp.13-19). Athens : Propompos. 
15. Cohen, L.; Manion, L. and Morrison, K. (2007). Research Methods in Education. 6th edition. Routledge.

16. Conrad, D. (2005). Building and Maintaining Community in Cohort -Based Online Learning. In Journal of Distance Education, 20(1), (pp. 1-20).

17. Dabbagh, N. (2004). Distance learning: emerging pedagogical issues and learning designs. In Quarterly Review of Distance Education, 5(1), (pp. 37-49).

18. Deschenes, A.J. (1996). Un programme d'initiation a la formation a distance de type constructiviste: Un réseau de communication pour l'apprentissage. In Distances, 1(2), (pp. 15 34). Retrieved on June 8, 2012 from http://cqfd.teluq.uquebec.ca/distances/D1_2_c.pdf

19. Dewey, J. and Bentley, A. (1949). Knowing and the Known. Beacon Press, Boston.

20. Dron, J.; Seidel, C. and Litten, G. (2004). Transactional distance in a blended learning environment. In ALT-F: Research in Learning Technology, 12(2), (pp. 163-174).

21. Dron,J. (2006). Social software and the emergence of control. In Proceedings of the sixth IEEE International Conference on Advanced Learning Technologies (ICALT 2006), (pp. 41-45). Kerkra, The Netherlands IEEE.

22. Dron, J. (2007a). Control and Constraint in e-learning: Choosing when to choose. Hershey, PA: Information Science Publishing.

23. Dron, J. (2007b). Designing the undesignable. Social software and control. In Educational Technology \& Society, 10(3), (pp. 60-71).

24. Farquhar, L. (2013). The intersection of dialogue and low transactional distance: considerations for Higher Education. In European Journal of Open, Distance and e-Learning, 16(2), 28-39. http:/ / www.eurodl.org/?p=archives\&year=2013\&halfyear=2\&article $=581$

25. Force, D. (2004). Relationships among transactional distance variables in asynchronous computer conferences: A correlational study. Unpublished Master Thesis Athabasca University.

26. Garrison, R. (2000). Theoretical challenges for Distance Education in the 21st century: A swift from structural to transactional issues. In The International Review of Research in Open and Distance Learning, 1(1), Retrieved on October 10, 2011 from:

http://www.irrodl.org/index.php/irrodl/article/viewFile/2/22

27. Garrison, D.R. (2009). Implications of online learning for the conceptual development and practice of distance education. In Journal of Distance Education, 23(2), (pp. 93-104).

28. Giossos, I. (2009). Validity and reliability of transactional distance in the framework of Hellenic Open University. Dissertation. Course: Studies in Education, School of Humanities, Patras, Hellenic Open University. (in Greek with English abstract)

29. Giossos, I.; Mavroidis, I. and Koutsouba, M. (2008). Research in distance education: review and perspectives. In Open Education, 4(1), (pp. 49-60). In Greek with English abstract.

30. Giossos, I.; Koutsouba, M.; Lionarakis, A. and Skavantzos, K. (2009). Reconsidering Moore's transactional distance Theory. In European Journal of Open Distance and ELearning, 2009(2), (pp. 1-6).

31. Gokool-Ramdoo, S. (2008). Beyond the Theoretical Impasse: Extending the applications of Transactional Distance Theory. In International Review of Research in Open and Distance Learning, (9)3.

32. Gunawardena, C.N. and McIsaac, M.S. (2004). Distance Education. In D.H. Jonassen (ed.), Handbook of research for educational communications \& technology, (pp. 355-395), (2nd Edition).

London: Lawrence Erlbaum Associates. 
33. Herbert, M. (2006). Staying the Course: A study in online student satisfaction and retention. In Online Journal of Distance Learning Administration, 9(4).

34. Hillman, D.C.; Willis, D.J. and Gunawardena, C.N. (1994). Learner interface Interaction in distance education: An extension of contemporary models and Strategies for practitioners. In The American Journal of Distance Education, 8(2), (pp. 30-42).

35. Jung, I. (2001). Building a theoretical framework of Web-based instruction in the context of distance education. In British Journal of Educational Technology, 32(5), (pp. 525-534).

36. Kanuka, H.; Collet, D. and Caswell, C. (2002). University instructor perceptions of use of asynchronous text-based discussion in distance courses. In The American Journal of Distance Education, 16(3), (pp. 151-167).

37. Lemone, K. (2005). Analysing Cultural Influences on E-Learning Transactional Issues. In G. Richards (ed.), Proceedings of World Conference on E-Learning in Corporate, Government, Healthcare, and Higher Education 2005, (pp. 2637-2644). Chesapeake, VA: AACE.

38. Liu, G.; Liu, Y.; Liang, G.; Song, J.; Liao, J.; Li, G. and Lin, M. (2004). Comparison of ELearning in Distance Education in Different Cultural Settings. In G. Richards (ed.), Proceedings of World Conference on E-Learning in Corporate, Government, Healthcare, and Higher Education 2004, (pp. 370-374). Chesapeake, VA: AACE.

39. Loizidou-Hatzitheodoulou, P.; Vasala, P.; Kakouris, A.; Mavroidis, I.; Tassios, T. (2001). Types of communication in distance learning and their contribution to the educational process. The case of the students of the postgraduate module "Open and Distance Education" of HOU. In the Proceedings - 1st Panbellenic Conference for Open and Distance Education (in Greek with English abstract).

40. Mavroidis, I.; Karatrantou, A.; Koutsouba, M.; Giossos, Y.; Papadakis, S. (2013). Technology Acceptance and Social Presence in Distance Education. A case Study on the Use of Teleconference at a Postgraduate Course of the Hellenic Open University. In European Journal of Open Distance and e-Learning, 16(2). Retrieved on November 27, 2013 from: http:/ / www.eurodl.org/?p=archives\&year $=2013 \&$ halfyear $=2 \&$ article $=590$

41. Moore, M.G. (1997). Theory of Transactional distance. In D. Keegan (ed.), Theoretical Principles of Distance Education, (pp. 22-38). New York: Routledge.

42. Moore, M. and Kearsley, G. (1996). Distance Education: A systems review. Belmont CA: Wadsworth Publishing Company.

43. Moss, D. (2004). Creating space for learning: Conceptualising women \& higher education through space \& time. In Gender \& Education, 16(3), (pp. 283-362).

44. Müller, T. (2008). Persistence of Women in on line Degree Completion Programs. In International Review of Research in Open \& Distance Learning, 9(2), (pp. 1-18).

45. Parrott, S. (1995). Future Learning: Distance Education in Community Colleges. ERIC Digest No. ED385311.

46. Pavlakis, A. and Kaitelidou, D. (2012) Burnout Syndrome in Students of a Distance Learning Program: The Open University of Cyprus Experience. In European Journal of Open, Distance and E-learning, 15(1). Retrieved on March 8, 2013 from: http:/ / www.eurodl.org/?p=archives\&year $=2012 \&$ halfyear=1\&article $=485$

47. Richardson, C.J. and Swan, K. (2003). Examining social presence in online courses in relation to students' perceived learning \& satisfaction. In Journal of Asynchronous Learning Networks, 7(1), (pp. 68-88). 
48. Rovai, A.P. and Baker, J.D. (2005). Gender Differences in Online Learning: Sense of community, perceived learning, and interpersonal interactions. In Quarterly Review of Distance Education, 6(1), (pp. 31-44).

49. Saba, F. and Shearer, R. (1994). Verifying key theoretical concepts in a dynamic model of distance education. In The American Journal of Distance Education, 9(1), (pp. 36-59).

50. Saenz, B.L. (2002). Students' perceptions of Social Presence and its value in Asynchronous Web-based Master's Instructional Program. PhD Thesis Virginia Polytechnic Institute and State University.

51. Sarakatsanou, E. (2007). Tutor-Student Communication at the Hellenic Open University. Students perceptions of two postgraduate course: Studies in Education and Adult Education. M.Ed Dissertation. Patras, Hellenic Open University (in Greek with English abstract).

52. Simpson, O. (2003). Student retention in online, open and distance learning. London: Kogan Page.

53. Stein, S.D.; Wanstreet, E.C.; Calvin, J.; Overtoom, C. and Wheaton, E.J. (2005). Bridging the Transactional Distance Gap in Online Learning Environments. In The American Journal of Distance Education, 19(2), (pp. 105-118).

54. Schellens, T. and Valcke, M. (2006). Fostering knowledge construction in university students through asynchronous discussion groups. In Computers \& Education, 46(4), (pp. 349-370).

55. Terre Blanche, M.; Durrheim, K. and Painter, D. (eds.) (2006). Research in practice: Applied methods for the social sciences. Cape Town: University of Cape Town Press.

56. Tait, A. (2003). Reflection on Student Support in Open \& Distance Learning. In The International Review of Research in Open \& Distance Learning, 4(1). Retrieved on February 2, 2011 from: http://www.irrodl.org/index.php/irrodl/article/viewArticle/134/214

57. Tzoutza, S. (2010). Face-to-face tutorials: The views of postgraduate students and their tutors at the Hellenic Open University. The case of postgraduate course on "Open and Distance Education” at Hellenic Open University. In Open Education, 6(1-2), (pp. 46-65). In Greek with English abstract.

58. Terhemba, N. (2006). Interactivity in distance education: The National Open University of Nigeria (NOUN) experience. In Turkish Online Journal of Distance Education - TOJDE, (7)4, Article 9. Retrieved on May 25, 2012 from: http://tojde.anadolu.edu.tr/tojde24/articles/article_9.htm

59. Wilson, T. and Whitelock, D. (1998). What are the perceived benefits of participating in a computer-mediated communication (CMC) environment for distance learning computer science students? In Computers \& Education, 36(3/4), (pp. 259-269).

60. Zhang, A. (2003). Transactional distance in web-based college learning environments: Toward measurement and theory construction. PhD Thesis. Virginia Commonwealth University. 